\title{
A Reappraisal of Global Soil Effective Temperature Schemes
}

\author{
Shaoning $\mathrm{LV}^{1,2}$, Yijian $\mathrm{ZENG}{ }^{1}$, Jun $\mathrm{WEN}^{2}$, Zhongbo $\mathrm{SU}^{1}$ \\ (1. Department of Water Resources, Faculty of Geo-information Science and Earth Observation (ITC), University of \\ Twente, P.O. Box 217, 7500AE, Enschede, The Netherlands; 2. Key Laboratory of Land Surface Process and \\ Climate Change in Cold and Arid Regions, Cold and Arid Regions Environmental and Engineering Research \\ Institute, Chinese Academy of Sciences, Lanzhou, Gansu 730000, China)
}

\begin{abstract}
:
Traditionally, Effective Soil Temperature $\left(T_{\text {eff }}\right)$ has been considered to be a secondary intermediate variable in microwave radiative transfer theory. However, its impact on microwave radiometry is comparable to that of vegetation cover, soil surface roughness and dielectric constant. $T_{\text {eff }}$ is defined as the weighted temperature of the emitting layers, where the weighting involved depends on the soil moisture profile. In this study, we evaluate the suitability of various models for estimating $T_{\text {eff }}$ using temperature and moisture profiles obtained from a land surface model. MERRA-Land (The Modern-Era Retrospective analysis for Research and Applications-Land) soil moisture profiles and temperature profiles were used to reproduce global $T_{\text {eff }}$ data sets with single parameter schemes (e.g. the Beta Soil Moisture Active Passive, SMAP scheme), two-parameter Choudhury's schemes (e.g. the current SMAP's scheme), two-parameter Wigneron schemes (e.g. the current Soil Moisture and Ocean Salinity scheme, SMOS), and multilayer $T_{\text {eff }}$ schemes (e.g. Lv's scheme). The results show that differences in $T_{\text {eff }}$ between these schemes are usually less than 5K. The comparison between Wigneron's and Lv's schemes indicates that, the difference is small (RMSD, root mean squared difference $<1 \mathrm{~K})$. In exceptional cases $(<1 \%)$, the RMSD between Choudhury's $T_{\text {eff }}$ scheme and Lv's scheme can reach around 5K. The Beta SMAP $T_{\text {eff }}$ has a difference of around 5K, compared to Lv's scheme. Such a change in $T_{\text {eff }}$ could lead to an emissivity difference of around 0.015. The most extreme emissivity difference is only found in desert areas, at $42.5^{\circ}$ (the incidence angle used by the SMAP mission is about $40^{\circ}$ ).
\end{abstract}

Key Words: effective soil temperature, Soil Moisture and Ocean Salinity (SMOS), Soil Moisture Active Passive (SMAP), soil moisture 


\section{Introduction}

Soil moisture is an essential variable in terrestrial water and energy budgets. A detailed knowledge of soil moisture has the potential to improve our current knowledge of hydrological processes and of seasonal climate forecasting (Hirschi et al. 2014; Su et al. 2014; Wen et al. 2014). Satellite microwave remote sensing is deemed to be the only feasible, direct method for retrieving data on global soil moisture levels. However, the accuracy of this method is heavily dependent on the sensors and retrieval algorithms used. The remote sensing of soil moisture by means of microwaves is based on the theory that the energy emitted from the soil is proportional to the thermodynamic temperature (Ulaby et al. 1983). The brightness temperature observed by satellite sensors is expressed as,

$$
T_{B}=\varepsilon T_{e f f}
$$

where $\varepsilon$ is the effective emissivity that corresponds to soil moisture, via the dielectric constant in radiative transfer models, and to vegetation conditions. $T_{e f f}$ is the effective soil temperature, which is influenced by soil moisture, wavelength and temperature (Wilheit 1978). In order to obtain $\varepsilon$ from Equation(1), a $T_{\text {eff }}$ value must be known a priori. On the other hand, the $T_{\text {eff }}$ used in current global operational processors for SMOS and SMAP was not obtained from direct measurements, but was instead taken from the modelled soil temperature profile. For example, the Soil Moisture and Ocean Salinity (SMOS) retrieval (Kerr et al. 2012) uses ECMWF (European Centre for Medium-Range Weather Forecasting) land surface model data. Similarly, the Soil Moisture Active Passive (SMAP) retrieval uses MERRA-Land, which is a land surface data product of the Modern-Era Retrospective analysis for Research and Applications (SMAP Algorithm Development Team and SMAP Science Team, 2015). The rational for deriving $T_{\text {eff }}$ from model simulation results is that the resultant errors are no more significant than those derived using a crude interpolation scheme, and will only have an impact in the case of very dry soils (Kerr et al. 2012).

More specifically, operational SMOS retrieval uses ECMWF simulations of global soil temperatures for the top layer and the deepest layer (or next to deepest layer), as the surface and deep temperatures, respectively. Wigneron's two-layer $T_{\text {eff }}$ scheme used these two soil temperatures as inputs, together with auxiliary information (Kerr et al. 2012). Similarly, the previous Beta SMAP retrieval assumed a homogenous soil temperature and soil moisture profile at 6:00 a.m. and 6:00 p.m. It also used the surface skin temperature and soil temperature at $0-10 \mathrm{~cm}$ derived from the MERRA-Land model as the surface 
and deep temperature, respectively (SMAP Algorithm Development Team and SMAP Science Team, 2015). The arithmetic average of these two temperatures is taken as $T_{\text {eff }}$. Since September 2015 , the SMAP team has updated its $T_{\text {eff }}$ using Choudhury's two-layer scheme. This was because preliminary analysis showed that a more sophisticated model was required for computing $T_{\text {eff }}$, due to non-uniform soil temperature profiles (O'Neill et al. 2015).

The use of soil temperatures from the various layers and models used for SMOS and SMAP may lead to differences in the values of $T_{\text {eff }}$ calculated by the two global processors. Recent investigations by Lv et al. (2014) indicated that the use of different sampling depths can result in a large deviation in $T_{\text {eff }}$ (around 7K at Maqu Network (Su et al. 2011)). This uncertainty may ultimately affect the final soil moisture product. One study (Sabater et al. 2011) reported that, in extreme cases, an error of $5 \mathrm{~K}$ in $T_{\text {eff }}$ can lead to a $5 \%$ error in the soil moisture product. Even when using the C-band, which is less sensitive to $T_{\text {eff }}$ parameterization than the L-band, accurate estimates of $T_{\text {eff }}$ are still essential for converting modelled emissivity into brightness temperature (Dente et al. 2014).

Thus, the primary objective of the current study is to compare the $T_{\text {eff }}$ results from the current SMOS and the SMAP schemes (both the Beta version and Choudhury's), and to examine their influence on emissivity (the intermediate variable directly related to soil moisture). The method and data discussed here will hopefully complement the SMAP mission that was launched in January 2015, thereby enhancing its ability to deliver global soil moisture products.

\section{Method and Data}

\section{a) MERRA-Land Data}

The Modern-Era Retrospective analysis for Research and Applications (MERRA) was a global atmospheric reanalysis undertaken by NASA/GMAO (Suarez et al. 2008). With the updated catchment land surface model and precipitation data, MERRA-Land provides a globally integrated, coherent estimate of soil moisture and temperature from 1979 to the present (Rienecker et al. 2011). In this study, hourly global soil moisture and temperature profiles were taken in 2013 to reproduce $T_{\text {eff }}$, using Lv's multilayer scheme (hereafter referred to as TM), the current SMOS scheme (e.g. a two-layer scheme, hereafter referred to as T2W), the SMAP scheme (hereafter referred to as T2C), and the Beta SMAP scheme (e.g. 
one layer scheme, hereafter referred to as T1). MERRA-Land has a spatial resolution of $0.67 \times 0.50$ degrees. This product makes it possible to create daily global $T_{\text {eff }}$ maps at 6:00 a.m. (ascending/descending for SMOS/SMAP) and 6:00 p.m. (descending/ascending for SMOS/SMAP) local solar time for all time zones. To enable soil moisture and temperature values to be acquired at the exact local solar time, all pixels are temporally interpolated according to their longitudes.

\section{b) SMOS Brightness Temperature}

The CATDS Centre (Centre Aval de Traitement des Données; http://catds.ifremer.fr/) SMOS level 3 brightness temperature $T_{B}$ products (SMOS L3C) were used to assess the influence of $T_{\text {eff }}$ on emissivity. It offers mean daily brightness temperature intensities set out in a grid with a resolution of $0.25 \times 0.3125$ degrees. SMOS L3C includes $\mathrm{V}$ and $\mathrm{H}$ full polarimetry $T_{B}$ at nadir incidence angles of between 0 and $65^{\circ}$. This study was restricted to an incidence angle of $42.5^{\circ}$, as this is close to the incidence angle of $40^{\circ}$ used by the SMAP mission. As horizontal polarization is primarily used in the context of soil moisture retrieval, this paper uses only $\mathrm{H}$ brightness temperature.

\section{c) Effective Temperature Models}

As indicated above, the $\mathrm{T} 1, \mathrm{~T} 2 \mathrm{C}, \mathrm{T} 2 \mathrm{~W}$ and $\mathrm{TM}$ schemes will be used to reproduce $T_{\text {eff }}$. The Beta SMAP $T_{\text {eff }}$ scheme (SMAP Algorithm Development Team and SMAP Science Team, 2015), referred to here as T1, is interpreted as a single layer $T_{\text {eff }}$ scheme. This is because it addresses neither sensing depth nor the weighting between a surface layer and a deeper layer. Theoretically, for the SMAP soil moisture retrieval algorithms, $T_{\text {eff }}$ is considered to be the average (or effective) temperature of the top $5 \mathrm{~cm}$ layer of soil. The $T_{e f f}$ is obtained from MERRA-Land data by taking the arithmetic mean of two parameters - TSURF (soil skin temperature at DZTS in Table 1) and TSOIL1 (soil temperature at DZGT1) - at their native value of $0.67 \times 0.50$ degrees. See Table 1 for a definition of TSOIL1 and other layering information used in the following description.

The updated SMAP $T_{\text {eff }}$ scheme (T2C) uses Choudhury's model as follows:

$$
T_{\text {eff }}=T_{\text {soil_deep }}+C\left(T_{\text {soil_top }}-T_{\text {soil_deep }}\right)
$$


where $T_{\text {soil_top }}$ refers to the soil temperature (TSOIL1) of MERRA-Land layer 1 (at a depth of 0-10 cm) and $T_{\text {soil_deep }}$ the soil temperature (TSOIL2) of MERRA-Land layer 2 (at a depth of $10-20 \mathrm{~cm}$ ). C=0.246 is given for $1.4 \mathrm{GHz}$ (Choudhury et al. 1982).

Table 1 MERRA-Land soil temperature/moisture data for layers 1-7, prepared as input for Equation (2). MERRALand also provides data on layers 8 and 9 , but this was not used in the present study.

\begin{tabular}{|c|c|c|c|c|c|c|c|c|c|c|}
\hline \multicolumn{2}{|c|}{ Layer } & 1 & 2 & 3 & 4 & 5 & 6 & 7 & 8 & 9 \\
\hline \multirow{2}{*}{$\begin{array}{c}\text { Soil } \\
\text { Moisture }\end{array}$} & $\begin{array}{c}\text { Variable } \\
\text { Name }\end{array}$ & \multicolumn{2}{|c|}{$\mathrm{DZSF}^{1}$} & \multicolumn{4}{|c|}{$\mathrm{DZRZ}^{2}$} & \multirow{2}{*}{\multicolumn{3}{|c|}{ None }} \\
\hline & Depth(m) & \multicolumn{2}{|c|}{$0-0.02$} & \multicolumn{4}{|c|}{$0.02-0.3401$} & & & \\
\hline \multirow{2}{*}{$\begin{array}{c}\text { Soil } \\
\text { Temperature }\end{array}$} & $\begin{array}{c}\text { Variable } \\
\text { Name }\end{array}$ & $\begin{array}{c}\text { DZTS }^{3} \\
\text { (TSURF) }\end{array}$ & & & $\begin{array}{c}\text { DZGT2 } \\
\text { (TSOIL2) }\end{array}$ & $\begin{array}{c}\text { DZGT3 } \\
\text { (TSOIL3) }\end{array}$ & \multicolumn{2}{|c|}{ DZGT4 } & DZGT5 & DZGT6 \\
\hline & Depth(m) & $\begin{array}{c}0 \\
-0.018\end{array}$ & \multicolumn{2}{|c|}{$\begin{array}{c}0.018 \\
-0.0988\end{array}$} & $\begin{array}{c}0.0988 \\
-0.294\end{array}$ & $\begin{array}{c}0.294 \\
-0.6799\end{array}$ & \multicolumn{2}{|c|}{$\begin{array}{r}0.6799 \\
-1.4425\end{array}$} & $\begin{array}{c}1.4425 \\
- \\
2.9496\end{array}$ & $\begin{array}{c}2.9496 \\
-10\end{array}$ \\
\hline
\end{tabular}

1 DZSF: Thickness of soil layer associated with top soil layer soil moisture content.

2 DZRZ: Thickness of soil layer associated with root zone soil moisture content.

3 DZTS: Thickness of soil layer associated with non-snow surface temperature components.

4 DZGT: Thickness of soil layer associated with $i^{\text {th }}$ layer.

The current SMOS $T_{\text {eff }}$ scheme (T2W) can be interpreted as a two-layer $T_{\text {eff }}$ scheme. T2W is based on a physical explanation of parameter $C$ using a soil moisture information, $C=\left(\frac{W_{s}}{W_{0}}\right)^{b}$, where $W_{s}$ is the $0-3 \mathrm{~cm}$ surface soil moisture (this depth interval corresponds well with the effective soil moisture value contributing to soil emission in the $\mathrm{L}$ band), and $W_{0}$ and $b$ are semi-empirical parameters depending on specific soil characteristics. This is applicable under a conditions that the clay fraction should be $<0.6$ and the sand fraction $<0.5$ (Wigneron et al. 2008; Wigneron et al. 2001). In the SMOS ATDB (Kerr et al. 2014), the default setting is $W_{0}=0.3 \mathrm{~m}^{3} / \mathrm{m}^{3}$ and $b=0.3$. This default setting will be applied in this study.

The TM is the multilayer $T_{\text {eff }}$ scheme developed by Lv et al. (2014), which bridges the gap between the simplest two-layer model and the infinite integral model without using empirical parameters. In theory, with the increasing number of layers used, the TM can approach Wilheit's integral theory. The TM 
can be used to build the $T_{\text {eff }}$ map, using multilayer soil moisture data and soil temperature data (e.g. from MERRA-Land). The TM (Lv et al. 2014) can be expressed as:

$$
T_{e f f}=T_{1}\left(1-e^{-B_{1}}\right)+\sum_{i=2}^{n-1} T_{i}\left(1-e^{-B_{i}}\right) \prod_{j=1}^{i-1} e^{-B_{j}}+T_{n} \prod_{j=1}^{n-1} e^{-B_{j}}
$$

where $B_{i}=\Delta x_{i} \cdot \frac{4 \pi}{\lambda} \cdot \frac{\varepsilon_{i}^{\prime \prime}}{2 \sqrt{\varepsilon_{i}^{\prime}}} \cdot T_{1}, T_{i}$ and $T_{n}$ are the average soil temperatures of the $1^{\text {st }}, i^{\text {th }}$ and bottom layers. $\lambda$ is the wavelength, which for both SMOS and SMAP is $21 \mathrm{~cm}$ in the L-band. $\varepsilon_{i}^{\prime \prime}$ and $\varepsilon_{i}^{\prime}$ are dielectric constants computed from Mironov's model (Mironov et al. 2004; Mironov and Fomin 2009) using soil moisture and soil temperature data. $\Delta x_{i}$ is the soil layer thickness at which soil moisture and soil temperature are considered to be constant. In this application, this corresponds exactly to the layer depths defined in the MERRA model. Details of the soil layer definition used in MERRA are given in Table 1. The variable definition in Table 1 is also listed in the MERRA-Land handbook (Reichle 2012). Using Equation(3), all the soil moisture data and soil temperature data from MERRA-Land can be used to calculate $T_{\text {eff }}$. The soil moisture profile does not correspond to the soil temperature profile in MERRALand. This is because the catchment model does not have a traditional 'layer-based' structure, in which the layer depth associated with root zone moisture content is given as a temporally constant field (abbreviated to DZRZ, see Table 1). All schemes are listed in Table 2. 
Table 2 Different schemes used for calculating $T_{\text {eff }}$

\begin{tabular}{|l|l|l|}
\hline \multicolumn{1}{|c|}{ Name } & \multicolumn{1}{|c|}{ Parameterization } & \multicolumn{1}{|c|}{ Layers } \\
\hline T1 & $T_{\text {eff }}=\left(T_{1}+T_{\infty}\right) / 2$ & $\begin{array}{l}T_{1}=\text { TSURF } \\
T_{\infty}=\text { TSOIL1 }\end{array}$ \\
\hline T2C & $T_{\text {eff }}=T_{\infty}+\left(T_{1}-T_{\infty}\right) C, C=0.246$ & $\begin{array}{l}T_{1}=\text { TSOIL1 } \\
T_{\infty}=\text { TSOIL2 }\end{array}$ \\
\hline T2W & $T_{\text {eff }}=T_{\infty}+\left(T_{1}-T_{\infty}\right)\left(\frac{W_{s}}{W_{0}}\right)^{b}, \min \left[\left(\frac{W_{s}}{W_{0}}\right)^{b}, 1\right],\left\{\begin{array}{l}W_{0}=0.3 \\
b=0.3\end{array}\right.$ & $\begin{array}{l}T_{1}=\text { TSOIL1 } \\
T_{\infty}=\text { TSOIL3 } \\
W_{s}=\text { DZSF }\end{array}$ \\
\hline TM & $T_{\text {eff }}=T_{1}\left(1-e^{-B_{1}}\right)+\sum_{i=2}^{n-1} T_{i}\left(1-e^{-B_{i}}\right) \prod_{j=1}^{i-1} e^{-B_{j}}+T_{n} \prod_{j=1}^{n-1} e^{-B_{j}}$ & All \\
\hline
\end{tabular}

d) Dielectric Models

From the point of view from Equation (3), TM may be strongly dependent on the dielectric model, by affecting the weighting between layers. This is true for the simplest form of TM (the two-layer case) because the impact of the dielectric model will be amplified by the soil temperature difference between the two layers (Lv et al. 2014). However, this impact is minimized by the relatively small temperature differences between neighboring layers when additional layers are taken into consideration. The Mironov dielectric model was adopted by the SMOS mission for the purpose of emissivity computations. The Mironov model performs more effectively than the Dobson model (Dobson et al. 1985) or Wang and Schmugge's model (Wang and Schmugge 1980), especially at low microwave frequencies, because it requires less input and is based on a physical approach (Mialon et al. 2015). Section 3.2 compares Mironov's, Wang and Schmugge's, and Dobson's models with one another, to characterize this effect and to find out how different dielectric models affect $T_{\text {eff }}$.

e) Statistical Metrics

Three metrics were calculated using $\mathrm{T} 1, \mathrm{~T} 2 \mathrm{C}$ or $\mathrm{T} 2 \mathrm{~W}$ (e.g. $T_{\text {eff-x }}$, the soil effective temperature dataset to be compared to a reference set) and TM (e.g. $T_{\text {eff-ref }}$, the reference soil effective temperature 
dataset used with Mironov's model): (i) bias, (ii) root mean squared difference (RMSD), and (iii) emissivity difference (ED). The equations used to calculate the three indicators are as follows (AI-Yaari et al. 2014):

$$
\begin{aligned}
\text { bias } & =\overline{\left(T_{e f f-x}-T_{e f f-r e f}\right)} \\
R M S D & =\sqrt{\overline{\left(T_{e f f-x}-T_{e f f-r e f}\right)^{2}}} \\
E D & =\frac{T_{B-L 3 c}-\frac{T_{B-L 3 c}}{T_{e f f-x}}}{T_{e f f}}
\end{aligned}
$$

where $T_{B-L 3 c}$ is the SMOS L3c brightness temperature.

\section{Results and Discussions}

\subsection{Soil Temperature Profile}

This section examines the assumption, adopted by $\mathrm{T} 1$, that the soil temperature profile is homogenous. It also illustrates the applicability of T2W. As T2C depends solely on wavelength, it involves no assumptions or limitations.

The previous SMAP $T_{\text {eff }}$ scheme assumed that vegetation and soil temperature are equal for halforbits that involve equator crossing (descending) at 6:00 a.m. This meant that the terms for soil temperature and land surface temperature (referred to as $T_{s}$ ) could be used interchangeably SMAP Algorithm Development Team and SMAP Science Team, 2015). This assumption concerning local thermal equilibrium at 6:00 a.m. (and 6:00 p.m.) matches the in-situ measurements and numerical simulations (Su et al. 2013; Zeng et al. 2009a; Zeng et al. 2009b). This concept facilitates the determination of $T_{\text {eff }}$ from the soil temperature profile derived from MERRA-Land.

Figure 1 shows the RMSD between the soil temperatures at TSOIL1 and TSOIL3, as well as TSURF and TSOIL3 (see Table 1 for definition), using MERRA-Land data for 2013. At 6:00 a.m., the difference between the two layers (ca. 6K) is smaller (Figure 1a). The maximum RMSD (6K) appears only in the arid regions around the subtropics. At 6:00 p.m., for Central Asia and North America, the RMSD between TSOIL1 and TSOIL3 can reach about 8K (Figure 1b). With regard to the comparison between TSURF and TSOIL3, the mean differences are large outside of tropical areas at 6:00 p.m (>10K), which renders the assumption of 
local thermal equilibrium invalid (Figure 1c). The assumption of local thermal equilibrium is only approximately valid from the tropical to subtropical regions (c.a. 1K) at 6:00 p.m. (Figure 1d). In the temperate zones the differences between TSURF and TSOIL3 increases to $4 \mathrm{~K}$, and reaches $10 \mathrm{~K}$ in the boreal zone. Allowing for the assumption of local thermal equilibrium (SMAP Algorithm Development Team and SMAP Science Team, 2015), it seems that the average of TSURF and TSOIL1 is not sufficiently representative to be used in T1 (Beta version SMAP) for the calculation of effective temperature.
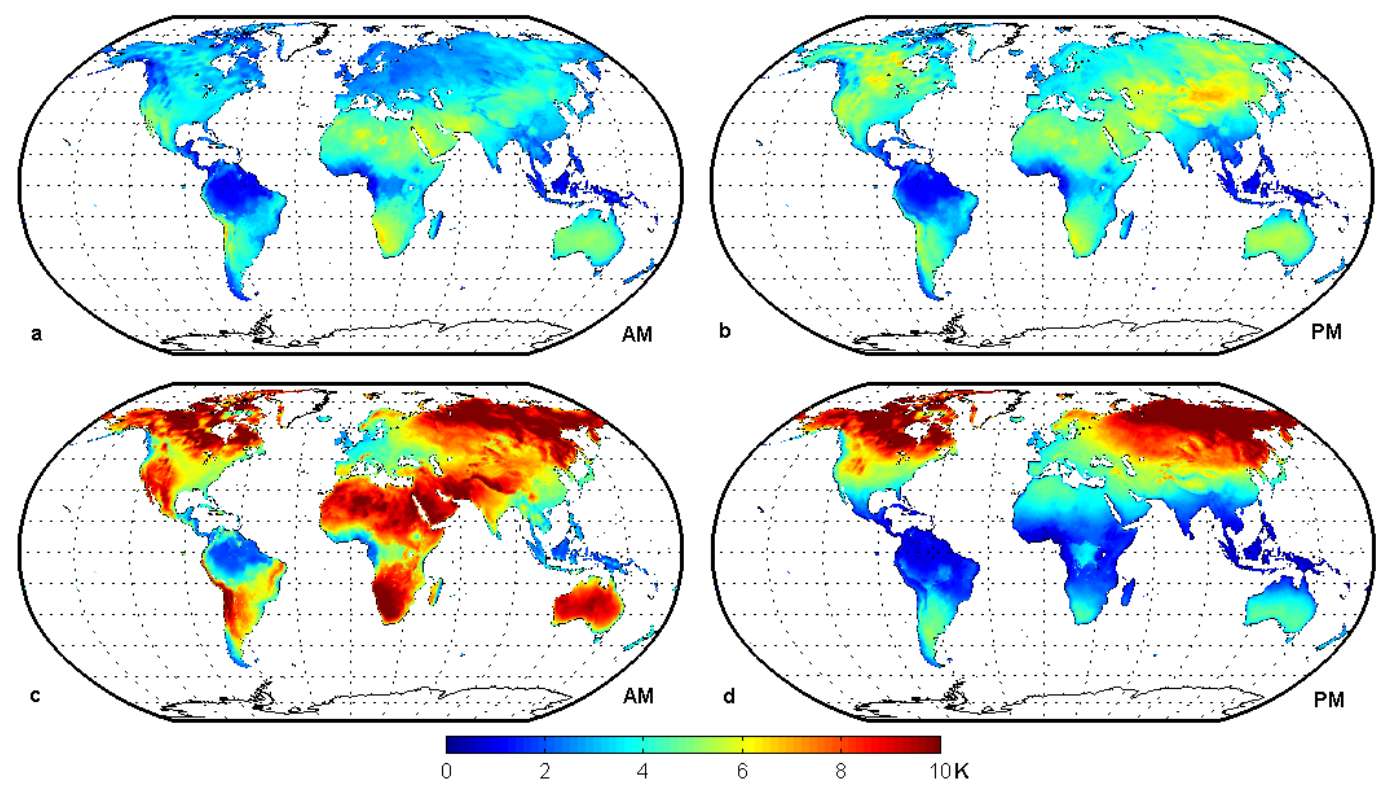

Figure 1 The soil temperature RMSD (K) of MERRA-Land for 2013 between a) TSOIL1 and TSOIL3 at 6:00 a.m.; b) TSOIL1 and TSOIL3 at 6:00 p.m.; c) TSURF and TSOIL3 at 6:00 a.m.; d) TSURF and TSOIL3 at 6:00 p.m..

Figure 2 shows the applicability of Wigneron's scheme at 6:00 a.m. and 6:00 p.m., based on MERRALand data. The blank areas are invalid regions, while the remaining areas are color coded to indicate the number of days on which the soil was frozen (TSOIL1<273.15-0.5K) in 2013. This shows that Wigneron's scheme cannot be used for $43.6 \%$ of the land area and for 67 days per pixel for the colored areas. 


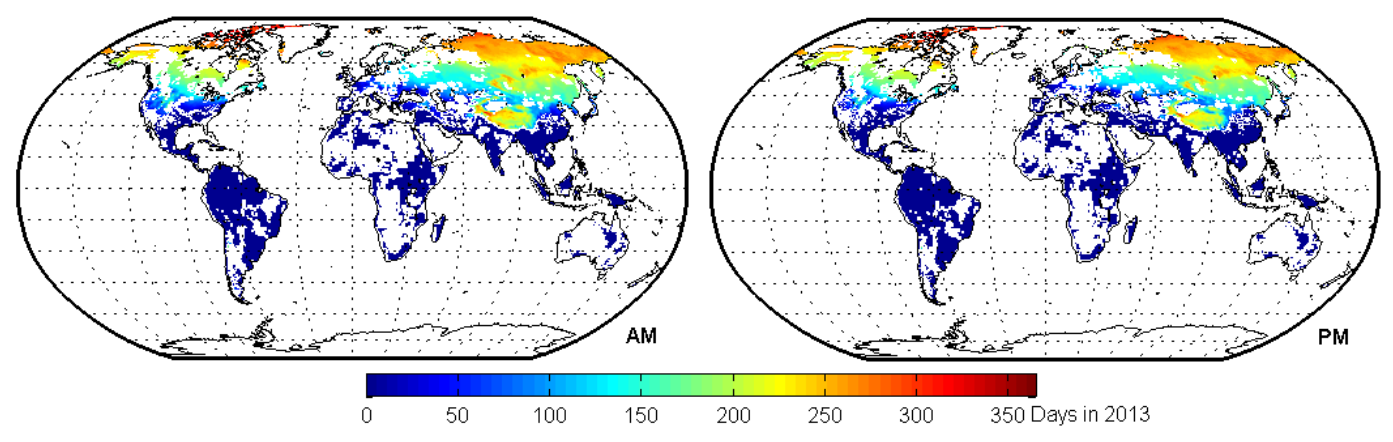

Figure 2 The applicability of Wigneron's scheme. The blank land area is invalid due to soil texture restrictions while the color coding indicates the number of invalid days in 2013 due to frozen soil.

\subsection{Comparison of Dielectric Constant Models}

The study by Lv et al. (2014), indicates that Lv's multilayer $T_{\text {eff }}$ can be applied to the full range of soil moisture conditions and corresponding weight ranges from 0 to 1, which are heavily dependent on the dielectric constant model used. Figure 3 shows that the bias (introduced by using either Wang and Schmugge's model or Dobson's model) in $T_{\text {eff }}$ calculated using TM is less than $1 \mathrm{~K}$ for most areas. The exceptions are subtropical deserts in Africa and Australia, as well as the northeastern part of North America (e.g. identified via comparisons between Figures $3 a$ and $3 b$ and Figures $3 c$ and $3 d$ ). Within these regions there is no significant difference between Dobson's model or Mironov's model in terms of the $T_{\text {eff }}$ values calculated using TM (bias $<1 \mathrm{~K}$ and RMSD $<1 \mathrm{~K}$, see Figures $3 \mathrm{c}$ and $3 \mathrm{~d}$, Figures $4 \mathrm{c}$ and $4 \mathrm{~d}$ ). In general, the bias and RMSD resulting from the use of different dielectric constant models are less than $1 \mathrm{~K}$, except in the case of arid or frozen areas (less than 35\% for the total land mask). To ensure that comparisons are consistent, the color bar used in Figures 3 and 4 has the same range as in other bias and RMSD maps. 

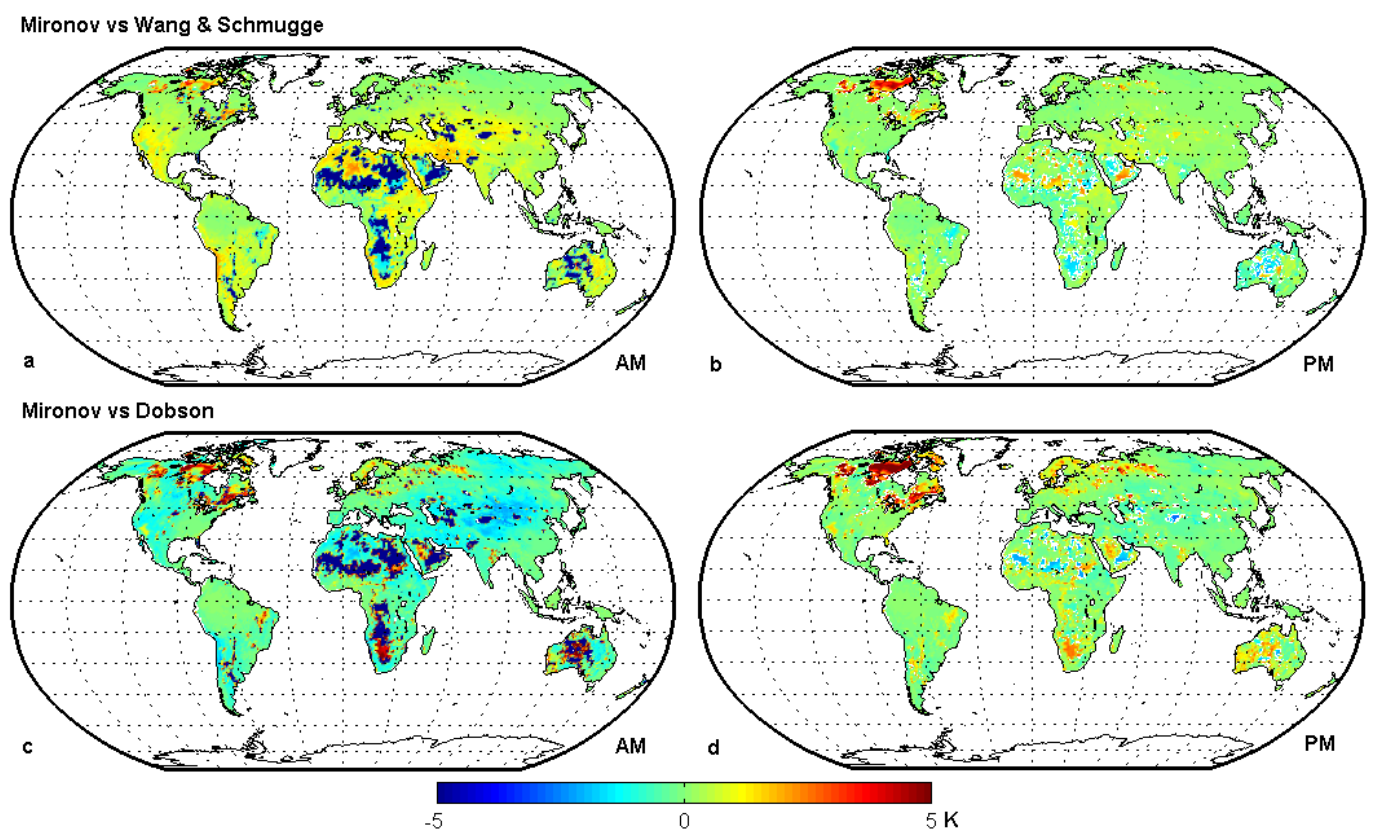

Figure 3 The annually averaged bias (K) between the $T_{\text {eff }}$ value calculated by TM using Mironov's dielectric constant model vs. that of Wang and Schmugge ( $a$ and $b$ ), and between Mironov's model and Dobson's ( $c$ and d). The data used was from MERRA-Land and frozen/thaw days are not included.
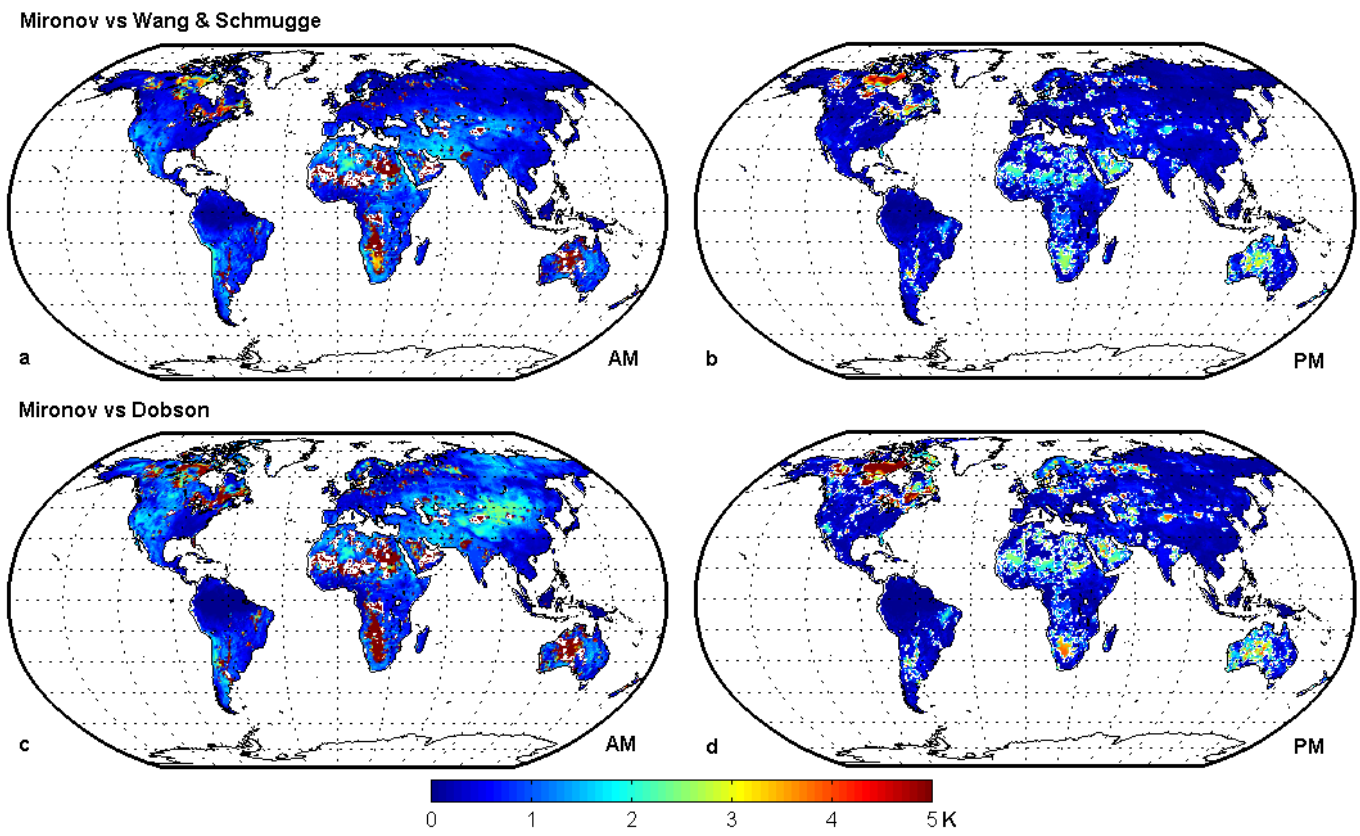

Figure 4 The RMSD (K) between the $T_{\text {eff }}$ value calculated by TM using Mironov's dielectric constant model vs. that of Wang and Schmugge ( $a$ and b), and between Mironov's model and Dobson's ( $c$ and d), for 2013. The data used was from MERRA-Land and frozen/thaw days are not included. 


\subsection{Comparison of $T_{\text {eff }}$ schemes}

In this section, TM is used as the reference scheme $\left(T_{\text {eff-ref }}\right)$ as it achieves the best approximation of Wilheit's integral theory when using all the available soil moisture data and soil temperature data from MERRA-Land. Bias and RMSD throughout 2013 were calculated to assess the performance of different $T_{\text {eff }}$ schemes relative to the result obtained using the reference scheme. Furthermore, TM will be used to analyze each layer's contribution to the calculation of $T_{\text {eff }}$.
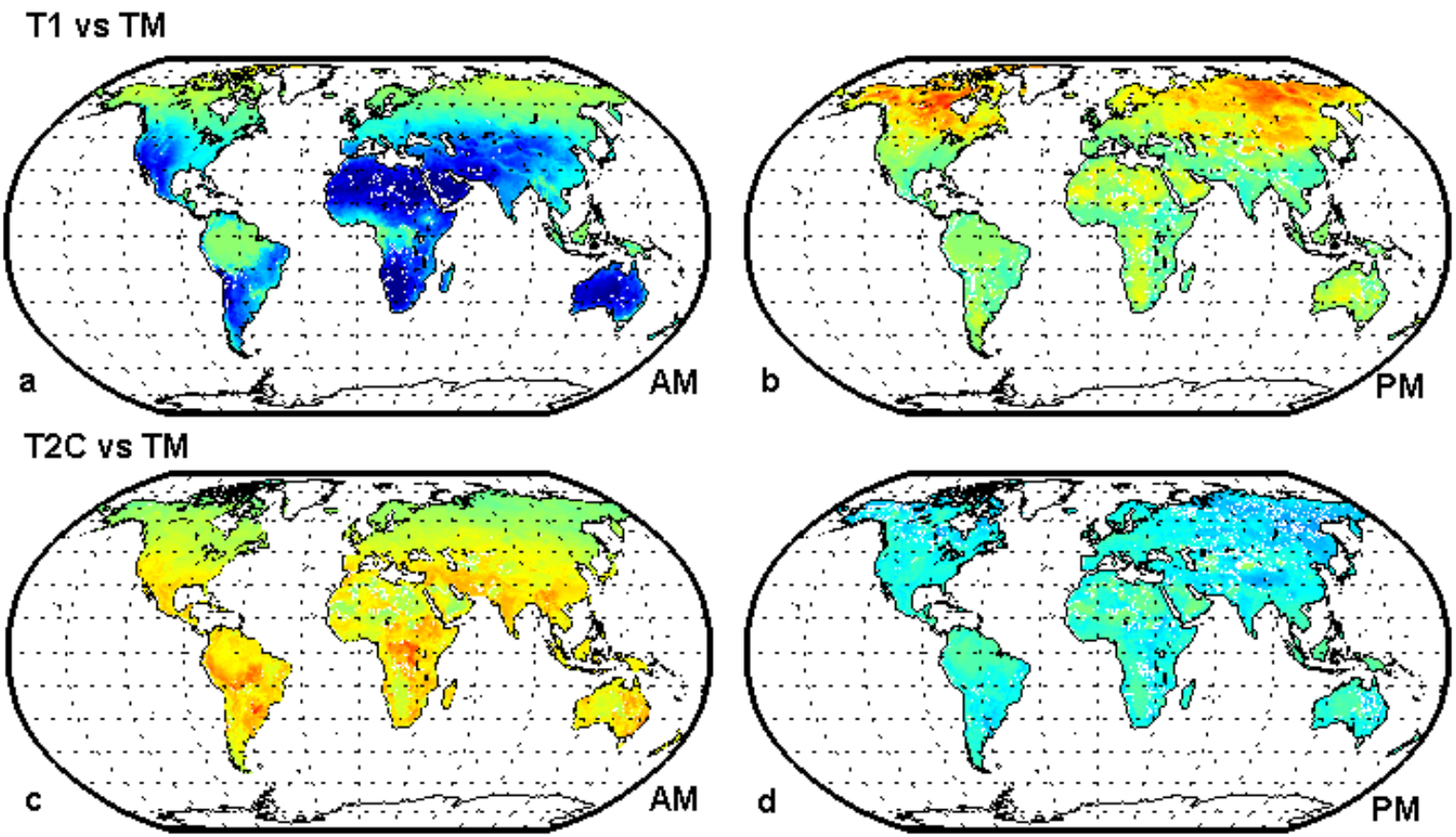

\section{T2W vs TM}

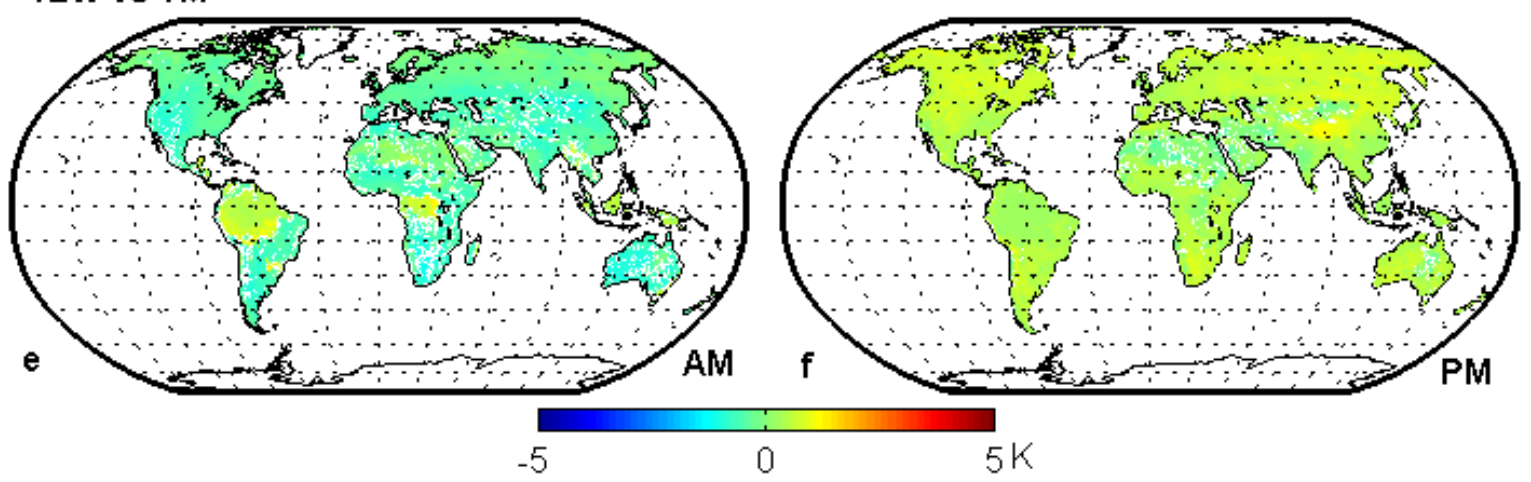

Figure 5 The annually averaged bias (K) between $T_{\text {eff }}$ calculated by T1 and TM ( $\mathrm{a}$ and b), T2C and TM (c and d), and T2W and TM (e and f). The data used was from MERRA-Land and frozen/thaw areas are not included. 
Deviations in $T_{\text {eff }}$ between $\mathrm{T} 1$ and TM, at 6:00 a.m. (descending) and 6:00 p.m. (ascending) are illustrated in Figures 5a and 5b. T1 is calculated using the average of TSOIL1 and TSURF, as indicated in Section 2 (c). T1 is lower at 6:00 a.m. but higher at 6:00 p.m. In general, the maximum bias of 5K is found in all continents, and even ranges up to $10 \mathrm{~K}$ in some areas. Those areas with a relatively large bias include not only arid and semi-arid regions (where the effect of $T_{\text {eff }}$ is thought to be significant, due to the greater sensing depth), but also vegetated land cover types such as crops and forest, where $T_{\text {eff }}$ is thought to be much less important. The bias between T2C and TM is much smaller than that between TM and T1 (Figures $5 c$ and $5 d$ ), declining from approximately $5 K$ to around $2 \sim 3 K$, except for areas at high latitudes.

Figures $5 e$ and $5 f$ show that the difference between $T_{\text {eff }}$ values calculated by $\mathrm{T} 2 \mathrm{~W}$ and by TM is quite small, it is less than 1.5K for most of the land area. In this study, we used MERRA-Land TSOIL1 soil temperature data for both $T_{\text {eff }}$ schemes. MERRA-Land data was used to facilitate consistent comparisons between SMOS and SMAP. Accordingly, when compared to TM, T2W gives a relatively low $T_{\text {eff }}$ value at 6:00 a.m. and a relatively high one at 6:00 p.m. $T_{\text {eff }}$ results obtained around the world by T2W and TM are very similar even in situations where Wigneron's scheme is invalid.

It is interesting to note that the greater difference in soil temperature observed between TSURF and TSOIL3 in high latitude regions (>10k in Figures $1 \mathrm{c}$ and $1 \mathrm{~d}$ ) does not lead to larger bias in $T_{\text {eff }}$, when compared to the corresponding values in Figures $5 \mathrm{a}$ and $5 \mathrm{~b}$. This is mainly due to the fact that frozen soil is included in Figure 1 while not in Figure 5. 


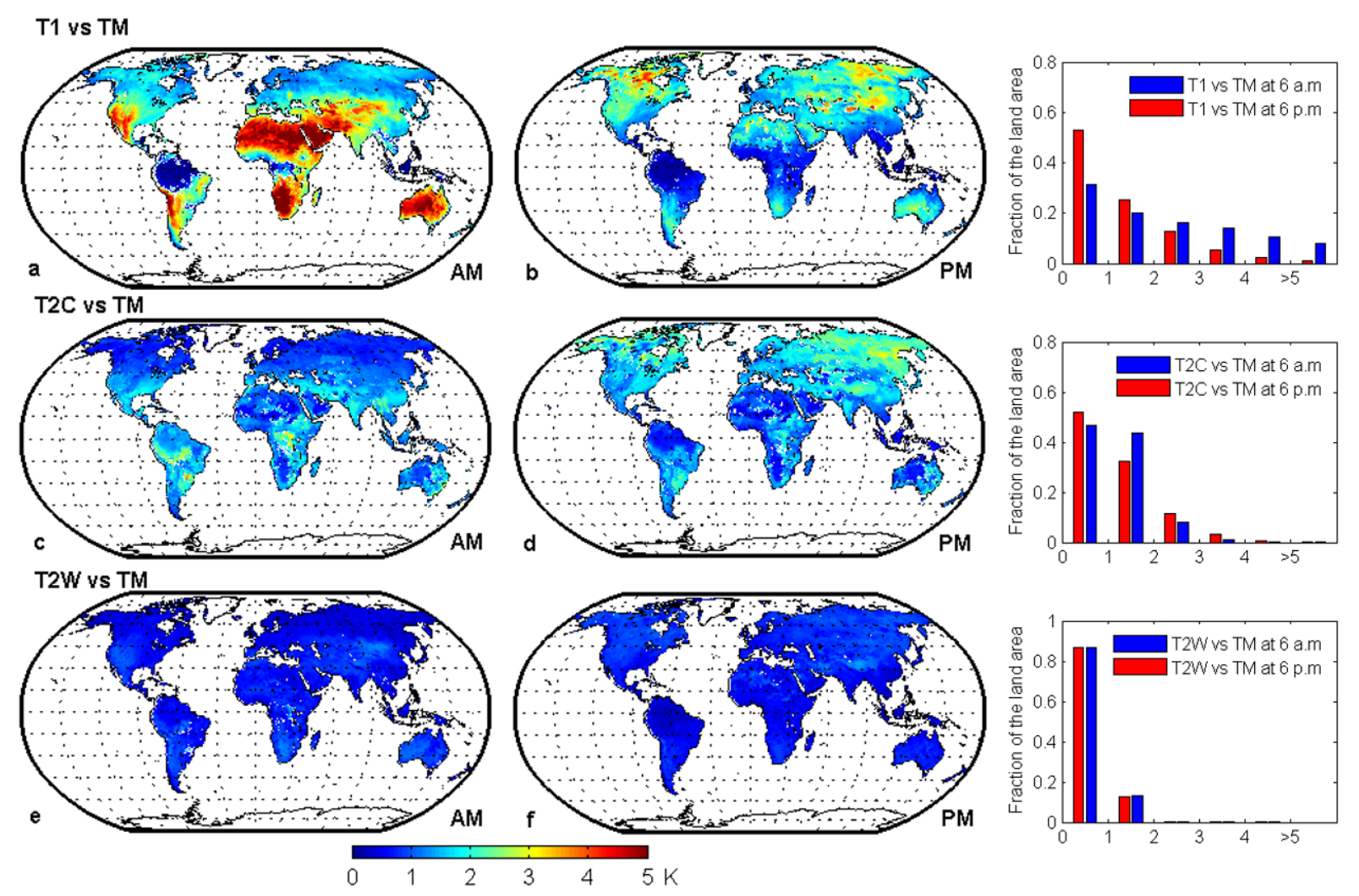

Figure 6 Global RMSD distribution(in K) between T1 and TM ( $a$ and b), T2C and TM (c and d), T2W and TM (e and f). The corresponding histograms are shown in the panels on the right. Frozen/thaw days are not included.

Figure 6 illustrates the differences between the various schemes in terms of root-mean-square deviation (RMSD). T1 shows the greatest deviation, both in terms of bias and of RMSD, relative to TM. At 6:00 a.m., regions with an RMSD in excess of $5 \mathrm{~K}$ are distributed around the globe, with the exception of high latitude areas of the Northern Hemisphere. By contrast, at 6:00 p.m., almost all regions (aside from high latitudes areas of the Northern Hemisphere) show a deviation of less than 5K. The RMSD distribution between T2C and TM, which corresponds to Figures $6 c$ and $6 d$, is intermediate to those between T2W and TM and those between T1 and TM. The RSMD exceeds $2 \mathrm{~K}$ in only 10 percent of the land area. With regard to the comparison between $\mathrm{T} 2 \mathrm{~W}$ and $\mathrm{TM}$, they are close to each other under any condition.

Any overestimation/underestimation of $T_{\text {eff }}$ will lead to a higher/lower brightness temperature in forward microwave radiative transfer modelling, resulting in dryer/wetter soil moisture estimates. Although any variation of the brightness temperature caused by $T_{\text {eff }}$ would be less than the variation in $T_{\text {eff }}$ itself, the bias in excess of 5K certainly cannot be ignored. According to (Parrens et al. 2014), while it 
is one order of magnitude lower than the uncertainty due to vegetation, roughness and soil moisture. 5K could involve a potentially error in the calculation of brightness temperature. The comparison in Figure 6 shows that large deviations can occur in the calculation of $T_{\text {eff }}$, potentially resulting in errors in the final soil moisture products. Nevertheless, the effect of this on $T_{\text {eff }}$ has been assumed to be negligible, relative to the error caused by soil temperature deviations (Kerr et al. 2012).

a
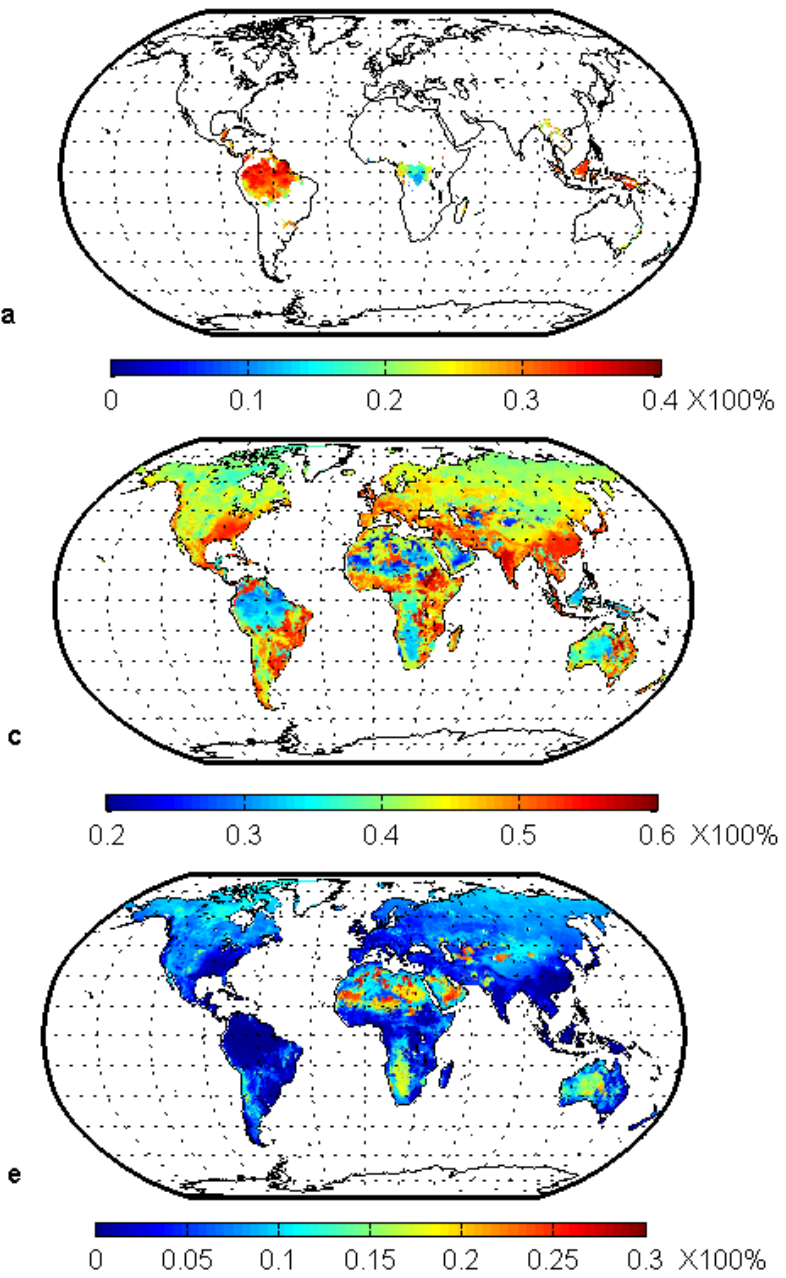

b
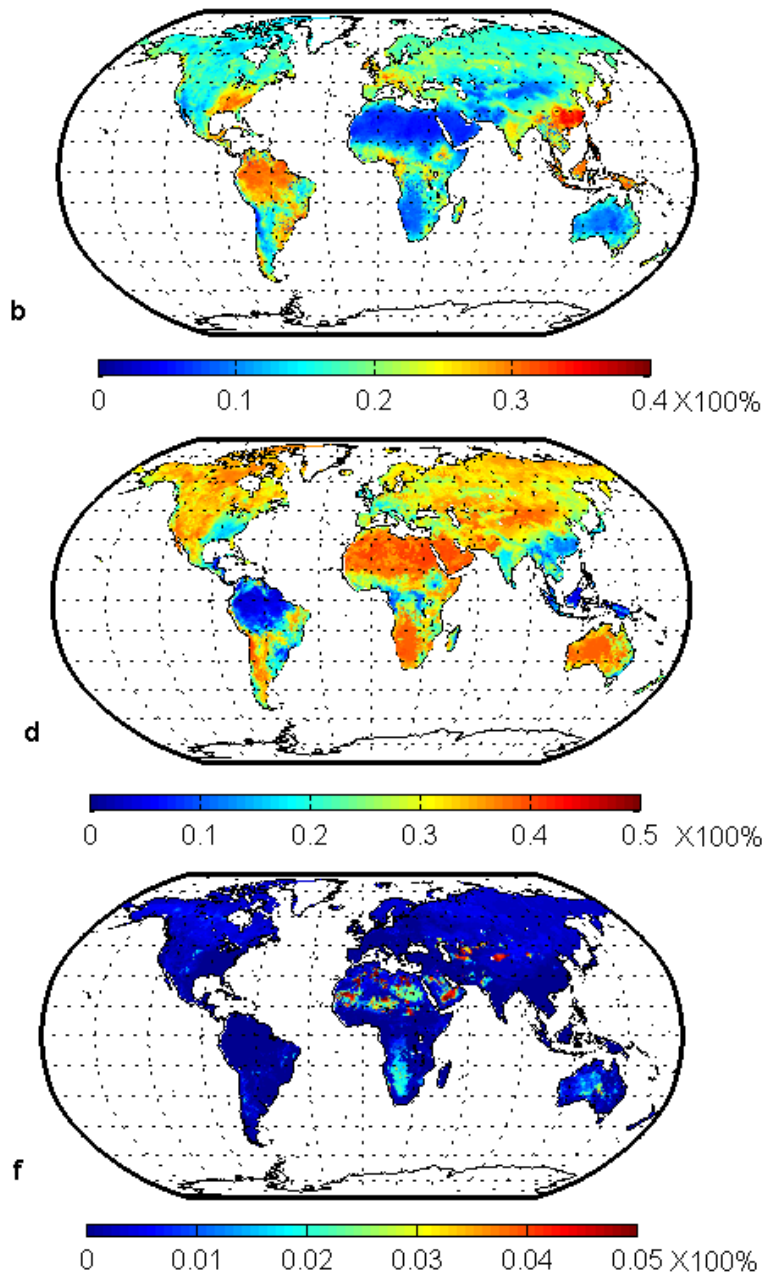

Figure 7 The annually averaged contribution of each layer in calculating $T_{\text {eff }}$. Their depths (a-f) correspond to the layers in Table 1 (Layers 1-6) as defined by MERRA-Land. Layers 7, 8 and 9 are not shown, as the small contribution from Layer $6(\mathrm{f})$ means that the contributions of underlying layers will be negligible.

Neither the current T1/T2C/T2W nor any other two-layer $T_{\text {eff }}$ schemes, such as Holmes's (Holmes et al. 2006), feature a multilayer approach. Thus, these schemes are restricted to using the MERRA-Land soil temperature data/moisture data for a single layer as their input, which means that potential contributions 
from other layers are ignored. From Wilheit's integral theory it can be inferred that, if the dielectric constant and the wavelength are changing, each layer's contribution will also vary. The weighting function (which describes each layer's contribution) should vary with soil moisture and soil temperature. TSOIL1 and TSOIL2 were selected as the inputs for T2C. While they perform relatively well, the physical reasons for this have yet to be explained. In view of the layer's signal contribution, an attempt has been made to account for this.

Using Equation (3), the temporal average contribution of each layer can be calculated by using $\left(1-e^{-B_{1}}\right)$ for the first layer, $\left(1-e^{-B_{i}}\right) \prod_{j=1}^{i-1} e^{-B_{j}}$ for the middle layers, and $\prod_{j=1}^{n-1} e^{-B_{j}}$ for the bottom layer. In MERRA-Land, soil temperature is defined for 7 layers (including surface soil temperature) with a certain fixed thickness (depth), while soil moisture uses 2 layers (DZSF and DZRZ) which vary for different pixels (Table 1). As shown in Table 1, layer 1 uses the soil moisture of DZSF and the soil temperature of DZTS. Layers 2 and 3 both use the temperature of DZGT1, together with the soil moisture of DZSF (layer 2) and DZRZ (layer 3). Layers 4, 5 and 6 use the soil moisture of DZRZ, together with the soil temperature of DZGT2, DZGT3 and DZGT4 (Table 1). There is no corresponding soil moisture data for layers 8 and 9, so these layers are not taken into account when using Lv's scheme. Even though the soil profile information provided by MERRA-Land cannot facilitate the straightforward application of Wilheit's theory, the treatment of soil layers (as indicated in Table 1) can be adopted to calculate the weighting of different layers (in terms of their contribution to calculating $T_{\text {eff }}$ ), using Lv's multilayer scheme.

Figure 7 gives an indication of the weighting of the contributions of layers 1 to 6 , listed in Table 1. The weighting of layer 1's contribution is small, only impacting a few tropical regions. As expected, the deeper layers (layers 2, 3 and 4 in Figures 7b, 7c and 7d) account for more than half of all contributions to $T_{\text {eff }}$ for most of the regions, although the weighting is unevenly distributed around the globe. Layers 4 and 5 are not involved in the SMAP scheme for calculating $T_{\text {eff }}$, while Figures $7 \mathrm{~d}$ and $7 \mathrm{e}$ indicate that these layers contribute at least $40 \%$ of all signals. In Wigneron's scheme, layer 5 is treated as the deeper layer, so its temperature contribution is partially included. This, therefore, results in less bias between T2C/T2W and TM than between T1 and TM (Figures 5 and 6). From Figure 7, it can be seen that the contribution from layer 6 is small (less than 5\%, Figure 7f), which means the soil temperatures in layers 7 , 8 and 9 (not shown in Figure 7) are negligible in terms of their contribution to $T_{\text {eff }}$. With regard to $T_{\text {eff }}$ model inputs, it is obvious that the contribution from the layer below $10 \mathrm{~cm}$ accounts for more than $60 \%$ 
(the sum of Layers 3 to 6 , Figures 7c/7d/7e/7f). Thus, as only TSURF and TSOIL1 are considered, the T1 model may not be appropriate. For T2C, TSOIL1 and TSOIL2 are taken as inputs corresponding to layers 2 to 4 (Figures $7 b / 7 c / 7 d$ ). The contribution of these three layers amounts to more than $80 \%$ and partly explains the improvements seen from $\mathrm{T} 1$ to $\mathrm{T} 2 \mathrm{C}$.

\subsection{Emissivity affected by $T_{\text {eff }}$ schemes}

In addition to the difference in $T_{\text {eff }}$ resulting from the use of different $T_{\text {eff }}$ computation schemes, the actual error in soil moisture introduced by the various $T_{\text {eff }}$ schemes (via emissivity) also needs to be quantified. In microwave remote sensing, emissivity is related to soil moisture (see Equation (1)). It also provides information that is valuable for monitoring other variables, such as salinity, frozen/thaw conditions, and sampling depth. For this reason, the 2013 MERRA-Land data were used to show the effect of $T_{\text {eff }}$ schemes on emissivity. In addition, the SMOS brightness temperature at an incidence angle of $42.5^{\circ}$ (which is close to the incidence angle used by the SMAP mission) was used in this analysis. Since SMOS's maximum revisit interval is 3 days, the 2013 SMOS L3c data have been merged to create a global map. Only the maximum emissivity values (either positive or negative) for regions covered by the satellite overpasses are shown here. The SMOS L3C data was re-projected from its original coordinate systems onto a regular grid, using a Nearest Neighbor approach to match it to MERRA-Land's EASE (Equal Area Scalable Earth) grid. Using the above configuration, we reproduced the emissivity differences between $\mathrm{T} 1 / \mathrm{T} 2 \mathrm{C} / \mathrm{T} 2 \mathrm{~W}$ and TM (Figure 8). Figure 8 only shows $\mathrm{H}$ polarization as this is relatively more important than $\mathrm{V}$ polarization in soil moisture retrieval, and because the $\mathrm{H}$ and $\mathrm{V}$ brightness temperature patterns are so similar to one another. 


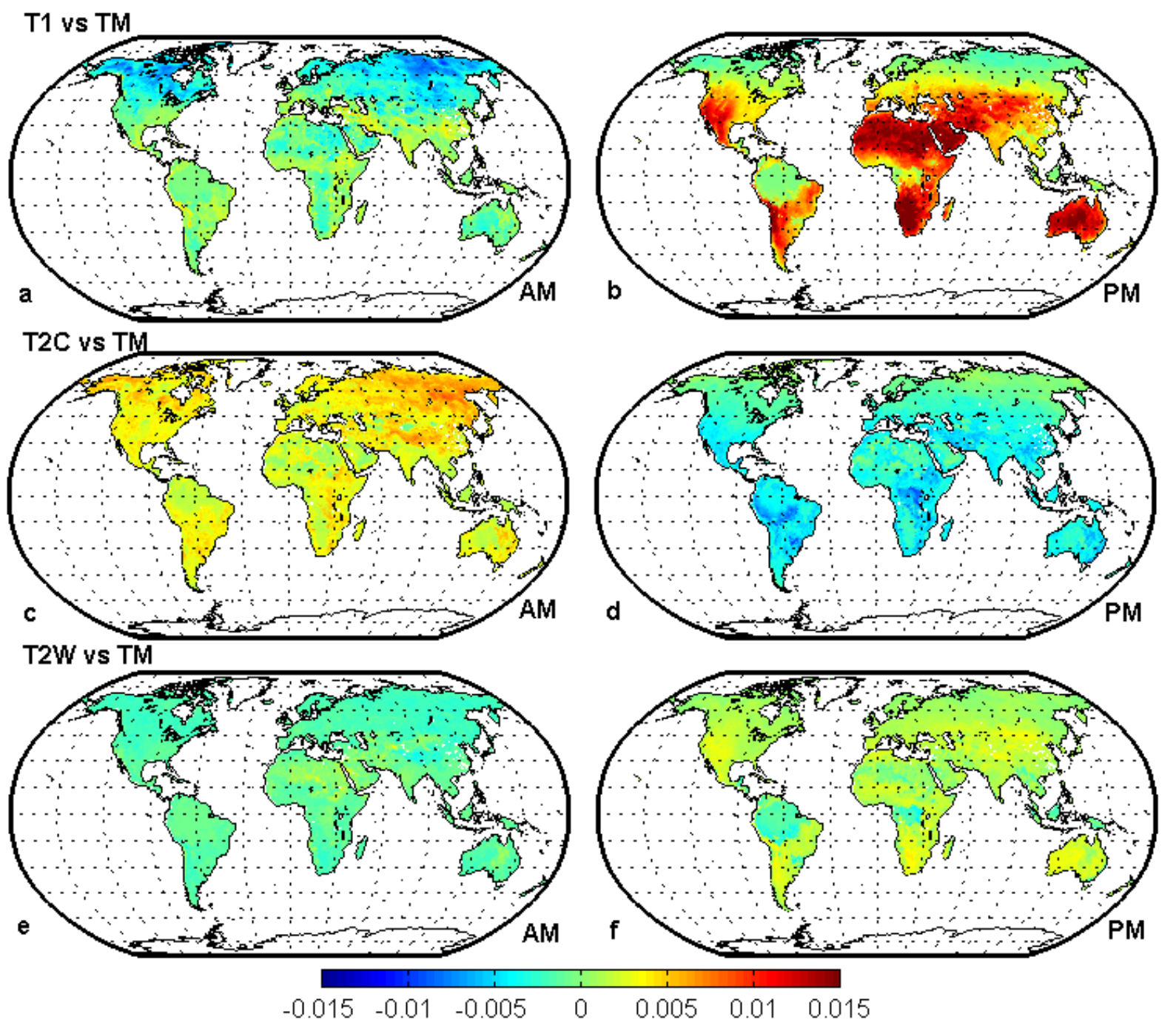

Figure $8 \mathrm{H}$ Polarization Emissivity Difference between various $T_{\text {eff }}$ schemes. Computed from MERRA-Land and SMOS L3c from July $1^{\text {st }}$ to $3^{\text {rd }}$, 2010. a) T1 vs TM, descending; b) T1 vs TM, ascending; c) T2C vs TM, descending; d) T2C vs TM, ascending; e) T2W vs TM, descending; f) T2W vs TM, ascending.

The variation of soil moisture can range from 0.01 to $0.04 \mathrm{~cm}^{3} \cdot \mathrm{cm}^{-3}$ for each 0.01 change in emissivity (Njoku and Entekhabi 1996; Panciera et al. 2014). Regions where the emissivity difference exceeds \pm 0.015 are marked in red/blue. For the comparison between T1 and TM, these regions include Siberia, Canada, the subtropical areas of Africa and Australia (Figures 8a and 8b). The total area with emissivity difference between T1 and TM greater than 0.01 is $0.04 \%(A M)$, and $16.56 \%(P M)$. When comparing T2C with TM (Figures $8 c$ and $8 d$ ) these areas are reduced to $0.01 \%$ (AM) and $0.03 \%$ (PM). This shows that the update in the SMAP processing from $\mathrm{T} 1$ and $\mathrm{T} 2 \mathrm{C}$ represents a large improvement. The 
areas with $>0.01$ emissivity difference are further reduced in the comparison between T2W and TM (Figures $8 \mathrm{e}$ and $8 \mathrm{f}$ ). This shows the merit of including a moisture dependent weighting factor.

\section{Conclusions}

If we compare the global distributions in bias and RMSD from various $T_{\text {eff }}$ schemes - SMOS (T2W), the beta version of SMAP (T1) and T2C, and Lv's multilayer scheme (TM) - the difference in $T_{\text {eff }}$ resulting from the use of different schemes was as much as $5 \mathrm{~K}$ for $\mathrm{T} 1$, but much lower for $\mathrm{T} 2 \mathrm{C}$ and $\mathrm{T} 2 \mathrm{~W}$. The differences relate not only to arid and semi-arid regions (where soil moisture is very low), but also to regions with other T1 land-cover types. Such differences can lead to different estimates of emissivity and, accordingly, of soil moisture. A comparison between T1 and TM reveals substantial bias and RMSD across the globe. Such a large difference or degree of uncertainty in calculating $T_{\text {eff }}$ can significantly affect soil moisture retrieval. In summary, the main findings are:

1) The contribution to $T_{\text {eff }}$ from the layer below $10 \mathrm{~cm}$, which is not addressed in the Beta SMAP scheme (T1), could be as high as $60 \%$ for most parts of the globe. By including deeper layers, T2C makes effective allowance for this contribution. The soil texture restriction is not important for T2W, which generates results similar to those obtained with TM.

2) The updated SMAP $T_{\text {eff }}$ calculation was improved by incorporating both TSOIL1 and TSOIL2 as input layers in the weighting function;

3) When using MERRA-Land data, the Lv multilayer $T_{\text {eff }}$ scheme is less dependent on the dielectric model. Only in desert areas can the effect of the soil dielectric model on the calculated $T_{e f f}$ reach $5 \mathrm{~K}$.

Acknowledgements. We acknowledge the financial support received from the National Science Foundation of China (Grant No. 41375022), the Key Research Program of the Chinese Academy of Sciences (Grant No. KZZD-EW-13) and the Chinese Scholarship Council (CSC) for Shaoning Lv. This work was also funded in part by the ESA MOST Dragon III program (Concerted Earth Observation and Prediction of Water and Energy Cycles in the Third Pole Environment (CEOP-TPE)), and the European Commission FP7 project CORE-CLIMAX (grant agreement No. 313085) and Opening Research Foundation of Key Laboratory of Land Surface Process and Climate Change in Cold and Arid Regions, Chinese Academy of Sciences (LPCC201406). 


\section{Reference}

Al-Yaari, A., Wigneron, J.P., Ducharne, A., Kerr, Y., de Rosnay, P., de Jeu, R., Govind, A., Al Bitar, A., Albergel, C., Munoz-Sabater, J., Richaume, P., \& Mialon, A. (2014). Global-scale evaluation of two satellite-based passive microwave soil moisture datasets (SMOS and AMSR-E) with respect to Land Data Assimilation System estimates. Remote Sensing of Environment, 149, 181-195

Choudhury, B.J., Schmugge, T.J., \& Mo, T. (1982). A Parameterization of Effective Soil-Temperature for Microwave Emission. Journal of Geophysical Research-Oceans and Atmospheres, 87, 1301-1304

Dente, L., Ferrazzoli, P., Su, Z., van der Velde, R., \& Guerriero, L. (2014). Combined use of active and passive microwave satellite data to constrain a discrete scattering model. Remote Sensing of Environment, 155, 222-238

Dobson, M.C., Ulaby, F.T., Hallikainen, M.T., \& Elrayes, M.A. (1985). Microwave Dielectric Behavior of Wet Soil .2. Dielectric Mixing Models. Ieee Transactions on Geoscience and Remote Sensing, 23, 35-46

Hirschi, M., Mueller, B., Dorigo, W., \& Seneviratne, S.I. (2014). Using remotely sensed soil moisture for land-atmosphere coupling diagnostics: The role of surface vs. root-zone soil moisture variability. Remote Sensing of Environment, 154, 246-252

Holmes, T.R.H., de Rosnay, P., de Jeu, R., Wigneron, R.J.P., Kerr, Y., Calvet, J.C., Escorihuela, M.J., Saleh, K., \& Lemaitre, F. (2006). A new parameterization of the effective temperature for $L$ band radiometry. Geophysical Research Letters, 33

Kerr, Y., Waldteufel, P., \& Richaume, P. (2014). Algorithm Theoretical Basis Document (ATBD) for the SMOS Level 2 Soil Moisture Processor Development Continuation Project. SMOS level, 2

Kerr, Y.H., Waldteufel, P., Richaume, P., Wigneron, J.P., Ferrazzoli, P., Mahmoodi, A., Al Bitar, A., Cabot, F., Gruhier, C., Juglea, S.E., Leroux, D., Mialon, A., \& Delwart, S. (2012). The SMOS Soil Moisture Retrieval Algorithm. Ieee Transactions on Geoscience and Remote Sensing, 50, 1384-1403

Mialon, A., Richaume, P., Leroux, D., Bircher, S., Al Bitar, A., Pellarin, T., Wigneron, J.P., \& Kerr, Y.H. (2015). Comparison of Dobson and Mironov Dielectric Models in the SMOS Soil Moisture Retrieval Algorithm. Ieee Transactions on Geoscience and Remote Sensing, 53, 3084-3094

Mironov, V.L., Dobson, M.C., Kaupp, V.H., Komarov, S.A., \& Kleshchenko, V.N. (2004). Generalized refractive mixing dielectric model for moist soils. Ieee Transactions on Geoscience and Remote Sensing, 42, 773-785

Mironov, V.L., \& Fomin, S.V. (2009). Temperature Dependable Microwave Dielectric Model for Moist Soils. In J.A. Kong (Ed.), Piers 2009 Beijing: Progess in Electromagnetics Research Symposium, Proceedings I and Ii (pp. 831-835). Cambridge: Electromagnetics Acad

Njoku, E.G., \& Entekhabi, D. (1996). Passive microwave remote sensing of soil moisture. Journal of Hydrology, 184, 101-129

O’Neill, P., Chan, S., Njoku, E., Jackson, T., \& Bindlish, R. (2015). Soil Moisture Active Passive (SMAP), Algorithm Theoretical Basis Document Level 2 \& 3 Soil Moisture (Passive) Data Products, Revison B 
Panciera, R., Walker, J.P., Jackson, T.J., Gray, D.A., Tanase, M.A., Ryu, D., Monerris, A., Yardley, H., Rudiger, C., Wu, X.L., Gao, Y., \& Hacker, J.M. (2014). The Soil Moisture Active Passive Experiments (SMAPEx): Toward Soil Moisture Retrieval From the SMAP Mission. Ieee Transactions on Geoscience and Remote Sensing, 52, 490-507

Parrens, M., Calvet, J.C., de Rosnay, P., \& Decharme, B. (2014). Benchmarking of L-band soil microwave emission models. Remote Sensing of Environment, 140, 407-419

Reichle, R. (2012). The MERRA-land data product. GMAO Office Note No. 3 (Version 1.2) Rienecker, M.M., Suarez, M.J., Gelaro, R., Todling, R., Bacmeister, J., Liu, E., Bosilovich, M.G., Schubert, S.D., Takacs, L., Kim, G.K., Bloom, S., Chen, J.Y., Collins, D., Conaty, A., Da Silva, A., Gu, W., Joiner, J., Koster, R.D., Lucchesi, R., Molod, A., Owens, T., Pawson, S., Pegion, P., Redder, C.R., Reichle, R., Robertson, F.R., Ruddick, A.G., Sienkiewicz, M., \& Woollen, J. (2011). MERRA: NASA's Modern-Era Retrospective Analysis for Research and Applications. Journal of Climate, 24, 3624-3648

Sabater, J.M., De Rosnay, P., \& Balsamo, G. (2011). Sensitivity of L-band NWP forward modelling to soil roughness. International Journal of Remote Sensing, 32, 5607-5620

Su, Z., de Rosnay, P., Wen, J., Wang, L., \& Zeng, Y. (2013). Evaluation of ECMWF's soil moisture analyses using observations on the Tibetan Plateau. Journal of Geophysical Research: Atmospheres, $118,5304-5318$

Su, Z., Fernandez-Prieto, D., Timmermans, J., Chen, X., Hungershoefer, K., Roebeling, R., Schroder, M., Schulz, J., Stammes, P., Wang, P., \& Wolters, E. (2014). First results of the earth observation Water Cycle Multi-mission Observation Strategy (WACMOS). International Journal of Applied Earth Observation and Geoinformation, 26, 270-285

Su, Z., Wen, J., Dente, L., van der Velde, R., Wang, L., Ma, Y., Yang, K., \& Hu, Z. (2011). The Tibetan Plateau observatory of plateau scale soil moisture and soil temperature (Tibet-Obs) for quantifying uncertainties in coarse resolution satellite and model products. Hydrology and Earth System Sciences, 15, 2303-2316

Suarez, M.J., Rienecker, M., Todling, R., Bacmeister, J., Takacs, L., Liu, H., Gu, W., Sienkiewicz, M., Koster, R., \& Gelaro, R. (2008). The GEOS-5 Data Assimilation System-Documentation of Versions 5.0.1, 5.1. 0 , and 5.2. 0

SMAP Algorithm Development Team and SMAP Science Team. (2015). Ancillary Data ReportSurface Temperature Version 2 SMAP Science Document no. 051

Ulaby, F.T., Razani, M., \& Dobson, M.C. (1983). Effects of vegetation cover on the microwave radiometric sensitivity to soil-moisture. Ieee Transactions on Geoscience and Remote Sensing, 21, 5161

Wang, J.R., \& Schmugge, T.J. (1980). An Empirical-Model for the Complex Dielectric Permittivity of Soils as a Function of Water-Content. Ieee Transactions on Geoscience and Remote Sensing, 18, 288295

Wen, J., Su, Z., Zhang, T., Tian, H., Zeng, Y., Liu, R., Kang, Y., \& Velde, R. (2014). New evidence for the links between the local water cycle and the underground wet sand layer of a mega-dune in the Badain Jaran Desert, China. Journal of Arid Land, 1-7 
Wigneron, J.P., Chanzy, A., de Rosnay, P., Rudiger, C., \& Calvet, J.C. (2008). Estimating the effective soil temperature at L-band as a function of soil properties. Ieee Transactions on Geoscience and Remote Sensing, 46, 797-807

Wigneron, J.P., Laguerre, L., \& Kerr, Y.H. (2001). A simple parameterization of the L-band microwave emission from rough agricultural soils. Ieee Transactions on Geoscience and Remote Sensing, 39, 1697-1707

Wilheit, T.T. (1978). Radiative-transfer in a plane stratified dielectric. Ieee Transactions on Geoscience and Remote Sensing, 16, 138-143

Zeng, Y., Su, Z., Wan, L., Yang, Z., Zhang, T., Tian, H., Shi, X., Wang, X., \& Cao, W. (2009a). Diurnal pattern of the drying front in desert and its application for determining the effective infiltration. Hydrol. Earth Syst. Sci., 13, 703-714

Zeng, Y.J., Wan, L., Su, Z.B., Saito, H., Huang, K.L., \& Wang, X.S. (2009b). Diurnal soil water dynamics in the shallow vadose zone (field site of China University of Geosciences, China). Environmental Geology, 58, 11-23 